\title{
ESCUELA DE LIBERALES: EL PERÍODO DE LAS CORTES DE CÁDIZ EN LOS MANUALES ESCOLARES PERUANOS (2010 Y 2017) ${ }^{1}$
}

\author{
SCHOOL OF LIBERALS: THE PERIOD OF LAS CORTES DE CADIZ \\ IN THE PERUVIAN TEXTBOOKS \\ (2010 AND 2017)
}

\begin{abstract}
Daniel Parodi Revoredo*
Esta investigación rastrea la presencia de la ideología nacionalista, de los valores del republicanismo y del liberalismo político en los manuales escolares publicados en Perú, entre los años 2010 y 2017, cuando se ocupan del período de las Cortes de Cádiz (1808-1815). Desde el enfoque del análisis crítico del discurso (ACD), y tomando en consideración el Diseño Curricular Nacional de Educación Básica Regular, se analizan tanto los relatos como las actividades didácticas de los manuales, se establece un diagnóstico y se ofrecen alternativas para reforzar las competencias ciudadanas -igualdad, libertad, participación, democracia- por medio de la enseñanza de este importante período histórico. Este trabajo es original tanto porque aplica el ACD a los contenidos de los manuales escolares de historia, porque indaga el desarrollo de competencias ciudadanas en sus páginas y porque los historiadores interesados en dichos manuales no han centrado su atención en el período materia de este estudio.

Palabras claves: Independencia, Constitución de Cádiz, enseñanza de la historia, educación ciudadana.

This investigation research the presence of nationalist ideology and the values of republicanism and political liberalism in school textbooks published in Peru, between 2010 and 2017, when dealing with the period of Las Cortes de Cádiz (1808-1815). From the critical discourse analysis (ACD)approach, and taking into account the National Curricular Design of Regular Basic Education, both the stories and the didactic activities of the manuals are analyzed, a diagnosis is established and some alternatives are offered to reinforce citizens competences to through the teaching of this historical period. This work is original because it applies the ACD to the contents of the history textbooks, because it investigates the development of citizen skills in its pages and because the historians interested in these manuals have not focused their attention on the subject period of this study.
\end{abstract}

Key words: Independence, teaching history, citizen education.

\section{Introducción}

La presente investigación indaga la presencia de la ideología nacionalista y de la enseñanza por competencias ciudadanas, vinculadas con los valores del liberalismo político, en los manuales escolares peruanos que tratan el período de las Cortes de Cádiz (1808-1815). Dicho período se inicia con la invasión napoleónica a España y se cierra con la vuelta al trono de Fernando VII de Borbón, quien se negó a firmar la Constitución de Cádiz de 1812 y reinstauró el absolutismo como modelo político en 1814 .

En investigaciones previas acerca de temáticas análogas hemos orientado nuestro enfoque mediante el análisis crítico del discurso histórico
(ACD). Este ha sido el caso de nuestros trabajos respecto de la Independencia del Perú, la Guerra del Perú y Chile contra España (1864-1866) y la Guerra del Pacífico (1879-1883). Además, dos de ellos pesquisan, bajo el mismo enfoque, los contenidos de los manuales escolares de educación secundaria en Perú y en Chile acerca de aquella.

Al mismo tiempo, hemos distinguido los dispositivos metatextuales que subyacen bajo las obras examinadas. Fue así que logramos establecer qué ideologías decimonónicas, como el positivismo histórico, el nacionalismo y el romanticismo literario -en adelante llamaremos a las tres ideología nacionalista-, constituyen el telón de fondo de todas ellas (Parodi, 2010, 2011, 2017, 2019).

* Universidad de Lima. Lima, Perú. Correo electrónico: Dparodi@ ulima.edu.pe 
Además, la presente investigación se ha visto enriquecida con los desarrollos acerca del concepto de alteridad, que atañe la relación entre un nosotros y un ellos. Al respecto, el concepto de otro cercano de Franco Catalani nos ha sido útil para comprender los roles asignados en el relato a peruanos, rioplatenses, neogranadinos; así como a los diferentes estamentos o castas coloniales así como criollos, mestizos, indígenas (Catalani, 2003).

La narración de los acontecimientos referidos opera en un escenario óptimo para la difusión de discursos patrióticos. Todas fueron guerras, todas tuvieron héroes que sacrificaron la vida por la patria. La Independencia constituye el lugar y el tiempo propicios para dotar al proyecto nacional de efemérides, bandera, himno, fronteras, tanto como de viriles caudillos a caballo que admirar. La Guerra del Pacífico, a su turno, es la oportunidad perfecta para construir al enemigo, al otro, lo que completa, en los casos peruano y chileno, la narrativa nacionalista.

Sin embargo, el período que de aquí en adelante llamaremos de las Cortes de Cádiz (1808-1815) se diferencia de aquellos otros porque abarca la década previa a la independencia del virreinato del Perú, cuyo virrey, Fernando de Abascal, convirtió en bastión de la resistencia realista, lo que dificulta la difusión de retóricas patrióticas en los relatos. De tal manera, un primer objetivo de la presente investigación es establecer hasta qué punto, y por medio de qué soportes metatextuales, la ideología nacionalista penetra en la narrativa histórica escolar.

Asimismo, entre el 2008 y 2015 se celebró el Bicentenario de las Cortes de Cádiz lo que motivó una eclosión de investigaciones acerca del período (Andújar, 2012; Bonilla, 2008; Campos, 2012; Cayuela, 2011; Landa, 2012; Peralta, 2008, 2010). El interés por esta temática vino acompañado con un cambio de enfoque que, en el Perú, podemos rastrear desde la publicación, en 1997, de La Utopía Republicana, de Carmen Mc Evoy (2018).

Desde entonces operó en nuestro medio una revisión de la historiografía anterior, que se enfocaba más en aspectos socioeconómicos, así como un redescubrimiento de la historia política que, distanciada del antiguo positivismo histórico, se centró en el estudio de la cultura y formas de representación políticas. La prioridad de este nuevo enfoque fue descubrir el pensamiento político en un período determinado por medio del lenguaje. González (2001) ubica el origen de esta nueva escuela historiográfica, en la publicación de El momento Maquiavélico, de J.G.A. Pocok, en 1973. A decir de González, para Pocok:

los rasgos definitorios de esta tradición, que arrancaría en Aristóteles, encuentran una reflexión paradigmática en el pensamiento de Maquiavelo, quien, en medio de un mundo político amenazado, cual era la República florentina del Renacimiento, habría acertado a destacar como elementos esenciales de la conciencia republicana los conceptos de balance de poderes en el gobierno y de virtud cívica (González, 2001: 2).

De esta manera, se indagaron fuentes primarias, como discursos o publicaciones periódicas, para recoger, de sus entrelíneas, las categorías políticas subyacentes. Para el caso que nos ocupa, las obras de Víctor Peralta constituyen un aporte fundamental porque aplican los tópicos referidos al período de las Cortes de Cádiz. En su balance historiográfico, Peralta subraya la reciente prioridad asignada al estudio de la representación y cultura políticas, y subdivide esta temática en cuatro grandes áreas de interés: los procesos electorales; la Constitución de Cádiz, los ayuntamientos y diputaciones que se crearon bajo su amparo; la cuestión étnica e interracial; y la nueva cultura política que resultó de la libertad de imprenta (Peralta, 2008: 76).

Esta última área nos lleva al segundo objetivo de nuestra pesquisa. Para Peralta, el período de las Cortes de Cádiz instaló en la colectividad peruana un nuevo repertorio conceptual que modeló las primeras representaciones e imaginarios políticos liberales. Asimismo, señala que el constitucionalismo gaditano difundió una nueva pedagogía política que impulsó la transición de una opinión pública literaria a otra política (Peralta, 2008: 87-88).

Redondeando estas ideas, "la cultura política en el virreinato pudo transformarse y modernizarse debido a la recepción del liberalismo hispánico" (Peralta, 2010: 17), mientras que el constitucionalismo español se convirtió en eje estructurante de los conflictos y cambios institucionales. Para el autor: 
... fue en la etapa del auge del liberalismo hispánico, es decir, durante los años que actuaron las Cortes de Cádiz, cuando definitivamente se transformaron los valores, las expectativas y las prácticas simbólicas que moldean las intenciones colectivas en el sistema político peruano (Peralta, 2010: 18).

En suma, los estudios acerca del período de las Cortes Cádiz publicados en el contexto de la celebración de su Bicentenario concluyen que durante aquel se advino al Perú un nuevo repertorio político en el que conceptos como soberanía popular, elecciones, libertad de imprenta, ciudadanía y virtud cívica (en adelante nuevo repertorio político liberal) se diseminaron, con distinta intensidad y diversas modalidades, por todos los estamentos sociales del virreinato. Este repertorio estableció las bases de una también nueva cultura política, la que se instaló, definitivamente, desde que se proclamase la independencia en 1821 y se adoptase el modelo republicano.

En tal sentido, nuestro segundo objetivo consiste en indagar si el referido enfoque se ha transferido a los contenidos de los manuales escolares peruanos. La pregunta es pertinente toda vez que, durante las dos últimas décadas, los programas escolares le han otorgado prioridad a la formación ciudadana, la que básicamente difunde los mismos valores republicanos que la nueva historia política busca levantar de las fuentes primarias y propagar por medio de sus investigaciones.

Este objetivo también explica nuestra elección de las obras de Víctor Peralta en desmedro de valiosos aportes que son más recientes, pues son las investigaciones de aquel las que aplican el giro historiográfico referido al período materia de nuestro estudio (O'Phelan, 2016, Guerra, 2018). Al mismo tiempo, los manuales escolares que pesquisaremos han sido publicados entre el 2010 y 2017 , por lo que indagaremos de qué manera el nuevo repertorio político liberal que instituyó el período de las Cortes de Cádiz, y que identifica Peralta en sus obras (2008 y 2010), se manifiesta en los contenidos de dichos manuales.

\section{Estado de la cuestión y metodología}

Mario Carretero (2004) sostiene que la enseñanza de la historia debe priorizar la promoción de valores ciudadanos y enfocarse desde competencias dirigidas a que los estudiantes valoren lo universal, regional y local, por encima de lo nacional. Luego, Parodi (2019) señala que la propia realidad latinoamericana, distinta de la europea, influye en la redacción de manuales escolares que recrean utopías nacionalistas. De hecho, las definiciones que se manejan en la región acerca de conceptos como soberanía, frontera y territorio distan de haberse actualizado o flexibilizado. Al respecto, Jorge Aguirre sostiene que los manuales de geografía instalan en los estudiantes las líneas fronterizas de la patria que es menester defender (Aguirre, 2015: 257-258).

A pesar de ello, como lo señalan Miralles y Gómez, una corriente revisionista comienza a incorporar, en la enseñanza de la historia, competencias ciudadanas como la virtud cívica y la educación para la paz (Millares y Gómez, 2017: 13). En todo caso, la tensión entre el viejo paradigma y el nuevo se expresa claramente en los contenidos de los manuales escolares. $\mathrm{Al}$ respecto, debemos reconocer que comenzamos con un hándicap pues el Diseño Curricular Nacional de Educación Básica Regular (en adelante DNC) no enfoca la enseñanza de la historia desde competencias ciudadanas relacionadas con el repertorio político del que hablamos. Más bien:

\section{El área de Historia, Geografía y Economía tiene como finalidad la construcción de la identidad social y cultural de los ado- lescentes y jóvenes, y el desarrollo de competencias vinculadas a la ubicación y contextualización de los procesos huma- nos en el tiempo histórico y en el espacio geográfico, así como su respectiva re- presentación (Ministerio de educación [MINEDU], 2008: 385) ${ }^{2}$.}

La no incorporación de competencias vinculadas a la democracia, desarrollo de ciudadanía, participación, elecciones, etc., en la enseñanza de la historia en el nivel de educación básica se explica en que ya existe en el currículo el curso de Formación ciudadana y cívica. Asimismo, el DNC recoge el artículo 8 de la Ley General de Educación que promueve la incorporación de valores democráticos y éticos. Además, se propone que los egresados desarrollen capacidades vinculadas con la ética, la moral, la democracia y la participación ciudadana (MINEDU, 2008: 19, 35). 
Esta pesquisa se organiza desde el método inductivo: partimos de los dos objetivos antes enunciados, que hemos planteado a manera de problematizaciones, los que se resolverán conforme se desarrolla la investigación. Luego, en la sección conclusiones explicaremos los resultados obtenidos, y ofreceremos reflexiones y propuestas respecto de la manera cómo los manuales escolares peruanos mejoran el tratamiento del período de las Cortes de Cádiz.

Respeto de las fuentes, hemos analizado un total de cinco manuales escolares: Hipervínculos 3 de Editorial Santillana (2012), Socio MundoCivilización: Historia, geografía y economía 3, de Antonio Guevara Espinoza, publicado por editorial Ebiolibros (2013), Encuentros 3 de SM (2014), Historia, Geografía y Economía 3 de Editorial Santillana (2015) y Descubre 3 de editorial Norma (2016). A estos se le suman tres manuales de difusión o preuniversitarios que ofrecen valiosa información de los discursos históricos materia del presente estudio. El primero de ellos es la Enciclopedia de Historia del Perú de editorial Bruño (2010), la que se ajusta a los programas escolares. Los otros dos, los más recientes, son Historia del Perú: una mirada actual del pasado de editorial Lumbreras (2017), y el Compendio de Historia de Perú de editorial San Marcos (2017), ambos manuales preuniversitarios.

Finalmente, hemos dividido el presente artículo en cinco partes organizadas bajo dos criterios: el cronológico y el temático. De esta manera, nos ocuparemos primero de las Juntas de Gobierno que se constituyeron como respuesta a la invasión napoleónica. Seguidamente indagaremos las Cortes y la Constitución de Cádiz. Luego evaluaremos las rebeliones que se produjeron durante este período, con énfasis en las de Tacna, Huánuco y Cusco (1811 y 1815), y concluiremos indagando el impacto del retorno del absolutismo al Perú. Además, hemos incluido a la presente un acápite que trata de las actividades didácticas y se pregunta hasta qué punto se vinculan a los repertorios nacionalista y liberal.

\section{La invasión napoleónica y las juntas de gobierno}

En 1807, el monarca Carlos IV de Borbón autorizó a las tropas napoleónicas atravesar España para invadir Portugal. La decisión real motivó el motín de Aranjuez que obligó a Carlos IV a abdicar en favor de su hijo Fernando VII, el 19 de marzo de 1808. Poco después, Napoleón Bonaparte capturó a ambos reyes en la localidad fronteriza de Bayona, donde obligó a Fernando VII a devolverle el trono a Carlos IV, y a este a abdicarlo a favor de José Bonaparte, el 6 de junio del mismo año.

Seguidamente, en Aranjuez, se constituyó la Junta Suprema Central y Gubernativa del Reino. Debido a los avances de las fuerzas napoleónicas, aquella debió trasladarse a la meridional Sevilla donde pudo mantenerse hasta el 30 de enero de 1810. Tras su disolución, y con prácticamente toda España invadida, se instaló en la Isla de León, litoral de Cádiz, el Consejo de Regencia de España. Seguidamente lo hicieron las Cortes de Cádiz, el 24 de septiembre del mismo año, con la finalidad de redactar una Constitución para España, convertir al reino en una monarquía constitucional, y adoptar los principios políticos liberales.

Estos acontecimientos afectaron a las colonias españolas en América. En varias de ellas se crearon juntas de gobierno análogas a la Junta Suprema Central. Sin embargo, aquellas rápidamente evolucionaron hacia posturas separatistas. El repentino cambio de posición de dichas juntas es destacado en los manuales escolares; así por ejemplo, Guevara sostiene que, mientras en España se resistía la invasión napoleónica:

... en las colonias españolas de América se formaban juntas de gobierno, lideradas por criollos de gran figuración. Inicialmente, las juntas se sujetaron a las autoridades españolas, solidarizándose con ellas ante el problema de la invasión. Pero luego se rehusaron a obedecerlas, convirtiéndose en foco de rebeliones e insurrecciones (Guevara, 2013: 88).

Varios manuales, como los de Guevara y SM, presenten información detallada de las juntas. Esto nos ha permitido conocer que en México la revolución de independencia manifestó un carácter más popular (Guevara, 2013: 91). Asimismo, se explica el caso de Caracas donde se instaló un Congreso Constituyente que, tempranamente, el 5 de julio de 1811, convirtió a Venezuela en una República Federal (SM, 2014: 94). 
Una polémica tradicional, y que se refleja en los manuales escolares, es la discusión en torno a la postura adoptada por los criollos peruanos, y en especial los limeños, respecto de las juntas de gobierno y del proceso independentista en general. Lumbreras aborda el tema desde un enfoque clasista:

Es de recordar el apoyo financiero que los comerciantes ricos de Lima, agrupados en el tribunal del Consulado, otorgaron a la campaña realista para combatir las juntas. Los criollos ricos de Lima preferían mantenerse fieles a la metrópoli y asegurarse así algunas viejas consideraciones y facilidades para su comercio (Lumbreras, 2017: 424).

Una postura más matizada es la de Santillana que sostiene que, a diferencia del separatismo de sus análogos americanos, en el virreinato del Perú se instauró una gran confusión frente a los sucesos de Bayona (Santillana, 2015: 118). Al respecto, se hace evidente en los manuales la inquietud por explicar por qué el Perú no optó por la emancipación, lo que se responde, la mayor de las veces, aludiendo la fuerte figura de su virrey Fernando de Abascal.

Al respecto, Guevara sostiene que la presencia de las fuerzas militares de Abascal en Lima y su plan para sofocar las rebeliones periféricas, impidieron la adopción de una firme postura separatista en el Perú (Guevara, 2013: 89). Por su parte, Hipervínculos destaca como, desde Buenos Aires hasta Caracas, se formaron juntas que desconocieron la autoridad española en América y señala que, en los virreinatos "más densamente poblados, como México y Perú", se mantuvo la fidelidad hacia las autoridades peninsulares (Santillana, 2012: 109).

El tratamiento de las juntas de gobierno americana en los manuales escolares peruanos nos deja dos ideas centrales. La primera es que casi no presentan una retórica nacionalista. Solo San Marcos señala que "La Junta de Buenos Aires presidida por Cornelio Saavedra envió expediciones hacia el Perú para apoyarnos en nuestra independencia", con lo que, al utilizar la primera persona del plural, relaciona semánticamente aquellos acontecimientos con los peruanos contemporáneos (San Marcos, 2017: 198). La ideología nacionalista asoma tímidamente en la preocupación que los relatos reflejan acerca de la participación de los peruanos en estos eventos, pero prevalece una narración bastante sobria de los acontecimientos.

Además, el nuevo repertorio político liberal está prácticamente ausente, salvo por la mención a la Constitución venezolana, o una nota de Norma que sostiene que, capturado el monarca español, la soberanía recayó en la población (Norma, 2016: 85). Por lo demás, las narraciones carecen de elementos suficientes para promover en el aula una discusión acerca del advenimiento del ideario liberal en el virreinato. Más bien, las preocupaciones que reflejan son las tradicionales: ¿qué postura adoptaron los criollos peruanos?, ¿por qué el virreinato del Perú no estableció una Junta de Gobierno en su ciudad capital?

\section{Las Cortes y la Constitución de Cádiz}

El 31 de enero de 1810, el Consejo de Regencia inició funciones en la Isla de León, Cádiz. Dicho Consejo convocó a elecciones a Cortes Generales -parlamento unicameral-que sesionaron desde el 24 de septiembre y promulgaron la Constitución de Cádiz el 19 de marzo de 1812. Desde entonces un nuevo repertorio político liberal se diseminó por Hispanoamérica.

Al tratar esta temática, los manuales centran su atención en dos cuestiones. La primera trata acerca de la igualdad de derechos obtenida. Guevara habla de una igualdad total entre españoles y americanos criollos, mestizos e indios (Guevara, 2013: 89). A su turno, Norma también subraya dichos derechos y relieva la figura del jurista limeño Vicente Morales Duarte, quien llegase a presidir las Cortes y murió cuando desempeñaba el cargo (Norma, 2016: 84).

Además, Hipervínculos 3 sostiene que "para los criollos, la convocatoria a las Cortes significó el reconocimiento de la importancia de su participación en el gobierno de la monarquía, situación que había sido restringida por las reformas borbónicas" (Santillana, 2012: 109). Sin embargo, subraya la inequidad en la representación en la asamblea, pues el número de diputados españoles era mucho mayor al de americanos, 267 frente a 37, respectivamente (Santillana, 2012: 109, Santillana, 2015: 121)1.

Esta inequidad es cuestionada en varios manuales. Hipervínculos 3 la pondera como una 
nueva discriminación y afirma que provocó una crisis de legitimidad en el Consejo de Regencia y las Cortes. Por esta razón, las juntas de gobierno americanas "desconocieron" dicha asamblea y optaron por el separatismo (Santillana, 2012: 109).

A su turno, Guevara sostiene que los diputados representaban "en su gran mayoría a España y en mucha menor proporción a sus colonias" (Guevara, 2013: 88). Al respecto, San Marcos menciona varios derechos concedidos a los americanos en las Cortes, pero subraya otros que les fueron negados como el libre comercio y la obligatoriedad de contratar al menos 50\% de americanos en los cargos públicos de los virreinatos (San Marcos, 2017: 199).

\section{Los contenidos de la Constitución de Cádiz y su impacto}

Al tratar la Constitución de Cádiz, los manuales escolares mencionan recurrentemente el nuevo repertorio político liberal. De esta manera, Guevara relieva las diferentes libertadas obtenidas desde su promulgación y comete la inexactitud de señalar que esta decretó la abolición de la esclavitud. Al respecto, el artículo 22 de la Constitución de Cádiz (1812) solo presenta ciertas condiciones para que los afrodescendientes pudiesen obtener la carta de ciudadanía (Guevara, 2013: 89).

A su turno, el texto de Norma señala que con "La Pepa" se conquistaron derechos fundamentales, los poderes se dividieron en ejecutivo, legislativo y judicial, y fueron abolidos los privilegios de nobleza (Norma, 2016: 84). Por su parte, Santillana refiere la monarquía constitucional, el gobierno representativo, la libertad de imprenta y la creación de provincias en lugar de virreinatos. Guevara destaca que la Constitución de Cádiz se constituyó en modelo para las que promulgaron, después, las repúblicas hispanoamericanas (Santillana, 2012: 121, Guevara, 2013: 89).

Finalmente, Hipervínculos 3 ofrece un apropiado resumen de los contenidos de la Constitución de Cádiz y de los derechos consagrados en ella:

\section{"La constitución de Cádiz}

Art. 1. La nación española es la reunión de todos los españoles de ambos hemisferios. (...)
Art. 5. La Nación está obligada a conservar y proteger por leyes sabias y justas la libertad civil, la propiedad y los derechos legítimos de todos los individuos que la componen $[\ldots]$.

Art. 18. Son ciudadanos aquellos españoles que por ambas líneas traen su origen de los dominios españoles de ambos hemisferios [...]. (Constitución Política de la Monarquía Española, 1812)" (Santillana, 2012: 109).

El desarrollo temático respecto de las Cortes y la Constitución de Cádiz nos merece dos comentarios: el primero es que los manuales escolares resaltan los derechos y libertades adquiridos por lo que presentan síntesis del articulado de la referida Constitución. En segundo lugar, la ideología nacionalista está casi ausente en los manuales, pues a este período se le enfoca más como un tema hispanoamericano que atañe la incorporación de una nueva cultura política en toda la región.

\section{Las rebeliones anticoloniales: Tacna, Huánuco y el Cusco}

Entre 1811 y 1815 se produjeron, al interior del virreinato peruano, varias rebeliones anticoloniales entre las que se destacan las de Tacna, Huánuco y Cusco. Estas se sitúan en el mismo contexto de las juntas y cabildos que, en Río de la Plata, la Nueva Granada y Chile, lograron la separación de España.

Al respecto, Hipervínculos 3 dedica unas líneas al fallido intento de los hermanos Silva de instaurar (1809) una junta de gobierno en Lima, homóloga a la española, la bonaerense y la caraqueña (Santillana, 2012: 120). Además, en los textos pesquisados hemos encontrado varias referencias a la rebelión de Francisco de Zela en Tacna (1811), respecto de esta se destacan dos aspectos. El primero es la participación de diferentes estamentos sociales en el levantamiento. Por consiguiente, Santillana sostiene que tras una victoria inicial "(...) los seguidores indios de este último, el cacique Toribio Ara y su hijo José, se codearon luego con los blancos y mestizos en el desfile triunfal realizado en la ciudad el 23 de junio" (Santillana, 2015: 129).

El segundo atañe la relación que se estableció entre los líderes de esta rebelión con los 
patriotas rioplatenses y sus campañas en el Alto Perú. La rebelión tacneña de 1811 se coordinó con el avance del bonaerense Antonio Gonzáles Balcarce, quien alcanzó las laderas del lago Titicaca, resultando allí derrotado por el general realista José Manuel de Goyeneche. El plan patriota consistía en unir las fuerzas rioplatenses y surperuanas para emancipar el sur del Perú y el Alto Perú, junto con Río de la Plata (Guevara, 2013: 95, Bruño, 2010: 296).

La rebelión del Cusco, dirigida por los hermanos Angulo y el cacique Mateo Pumacahua, que se produjo entre 1814 y 1815, acapara la mayor atención en los manuales. En primer lugar, se destaca su dimensión, pues se extendió a Puno, Arequipa y Ayacucho " (...) llegando incluso hasta el actual territorio de Bolivia" (Guevara, 2013: 96).

Un aspecto importante en esta temática es la Junta del Cusco. Se le llamó Junta de Gobierno de las Provincias Unidas del Sur y se instaló en agosto de 1814, luego de que los rebeldes apresasen a los miembros de la Audiencia (Santillana, 2012: 121). Sus miembros fueron elegidos por el cabildo bajo el marco legal de la Constitución de Cádiz. Su presidencia recayó en Pumacahua, también la integraron los hermanos Mariano, Vicente y José Angulo. En el Cusco se produjo, pues, un cambio de modelo político (Lumbreras, 2017: 426).

Por otro lado, varios manuales resaltan la composición multiétnica de la Junta del Cusco y de su subsecuente rebelión. Al respecto, Guevara sostiene que:

Pese a ser encabezada por el criollo José Angulo, logró convocar a distintos sectores sociales, conciliando intereses de criollos, mestizos e indios. Una muestra fue la participación del noble indígena Mateo Pumacahua, quien había luchado contra Túpac Amaru II, el cual se sumó a la causa independentista (Guevara, 2013: 76).

El carácter separatista de la Junta y la Rebelión del Cusco es destacado en los textos, los que las relacionan con sus pares que se instalaron en los virreinatos vecinos y que sí lograron separarse de España. También se señala el apoyo que los cusqueños recibieron desde Buenos Aires (Lumbreras, 2017: 426).

\section{Criollos vs. andinos, el otro debate}

En la narración de las rebeliones anticoloniales peruanas emerge el debate acerca de la participación de los diferentes estamentos coloniales y de los intereses defendidos por cada uno de ellos. Respecto de la rebelión tacneña, Santillana sostiene que los criollos de provincia eran más cercanos a los indígenas que los "refinados" criollos de Lima, lo que explicaría el carácter multiétnico de la rebelión (Santillana, 2015: 129).

Por otro lado, Santillana sostiene que en la rebelión de Huánuco de $1812^{2}$, que liderase Juan José Crespo y Castillo, criollos e indígenas manifestaron una postura crítica frente al Imperio español pero debido a motivaciones diferentes (Santillana, 2015: 127). Además, Santillana parafrasea al historiador Jorge Basadre quien sostuvo que, de haber triunfado la rebelión cuzqueña de 1814 , la nación peruana hubiese surgido de la conjunción de criollos, mestizos e indios, y su proceso social se hubiese caracterizado por una integración que la independencia definitiva, obtenida en 1824 , no pudo ofrecer debido a su dirección marcadamente criolla (Santillana, 2015: 129).

A su turno, Guevara refiere que el fracaso de la rebelión del Cusco implicó la desaparición de la nobleza indígena y que, quienes quedaron al frente, los criollos, "a pesar de inclinarse hacia las tendencias separatistas (...) seguían considerándose 'españoles americanos', y no se identificaban ni solidarizaban, necesariamente, con la situación de los habitantes andinos" (Guevara, 2013: 93). La brecha es más marcada para Lumbreras:

\section{Ya se ha visto que en el Perú colonial existen dos tendencias de lucha eman- cipadora, dos caminos que, en el fondo, corresponden a dos culturas, a dos siste- mas de vida: el indígena y el criollo. El primero de ellos, con raíces profundas en el Perú, heredero de la cultura andina; el segundo, con la mirada hacia Europa, que catalogaba a España como la Madre Patria (Lumbreras, 2017: 427).}

Seguidamente, Santillana sostiene que los criollos buscaban expulsar a las autoridades peninsulares para reemplazarlas, al mismo tiempo que mantenían su fidelidad al rey Fernando VII, mientras que los indígenas apuntaban hacia la 
reinstauración de formas de gobierno anteriores a la conquista (Santillana, 2015: 127). Finalmente, Bruño plantea que las aristocracias española y criolla tendían a apoyar al bando vencedor para garantizar así la seguridad personal y de sus bienes. Añade que no poseían ninguna vocación separatista (Bruño, 2010: 299).

Para concluir, notamos que se abre paso en el relato una mirada regional del proceso, tanto en lo relativo a provincias o ciudades periféricas a la capital Lima, como Huánuco o Tacna, como respecto de todo el espacio hispanoamericano. Por ello, resultan sugerentes las referencias a movimientos que relacionaron a los separatistas del sur del Perú con sus homólogos bonaerenses, y los esfuerzos que realizaron por conectarse por medio del Alto Perú.

Asimismo, nuestra búsqueda de la ideología nacionalista en las narraciones ha arrojado resultados confusos. Pareciese que se juzga la participación de diferentes sectores en estos acontecimientos, a base de su menor o mayor vocación separatista. De allí que las mayores críticas se dirijan a los criollos, particularmente los de Lima, por su postura renuente a la emancipación.

Al tratar las rebeliones, los manuales colocan su énfasis en una polémica validada por la compleja transición de una sociedad estamental a otra republicana, teóricamente basada en el principio de igualdad. De hecho, hasta hoy no se ha cerrado el debate respecto de si somos sociedades igualitarias en los planos civil, político y social.

Finalmente, llama la atención que el nuevo repertorio político liberal desaparezca de los manuales cuando tratan las rebeliones anticoloniales, pues se le da por establecido cuando se habla de separatistas o patriotas. De hecho, se deja pasar la oportunidad de fomentar la discusión respecto de los programas políticos de estos levantamientos. Notemos que en el Cusco se instituyó una Junta de Gobierno con características análogas a las de Buenos Aires o Caracas, por lo que se extraña una mayor profundización en el estudio de sus características institucionales, tanto como de la circulación de idearios republicanos y liberales.

\section{La reacción absolutista}

Mientras España permaneció regentada por José Bonaparte (1808-1813); en América del Sur, el virrey Fernando de Abascal realizó denodados esfuerzos por evitar la emancipación de las colonias y combatir el ideario liberal de las Cortes y la Constitución de Cádiz. Expulsadas las tropas napoleónicas de la península, Fernando VII de Borbón ingresó triunfalmente a Madrid el 22 de marzo de 1814. El monarca se negó a jurar la Constitución de 1812, reinstauró el modelo absolutista e inició una campaña para socavar los avances liberales y recuperar las colonias perdidas.

Al respecto, Guevara explica cómo la reacción absolutista fue cobrando fuerzas conforme mermaba el poderío napoleónico. Sostiene que, tras la derrota del emperador francés en Waterloo (junio de 1815), dicha reacción conservadora se consolidó con la conformación de la Santa Alianza entre Prusia, Rusia y Austria (Guevara, 2013: 88).

Asimismo, Norma señala que Fernando VII intentó reinstaurar el absolutismo, pero que la difusión del ideario liberal en España inició un período de inestabilidad política y convulsiones sociales (Norma, 2016: 84). A su turno, Guevara precisa los objetivos político-militares de Fernando VII en Hispanoamérica y señala que los triunfos ante las fuerzas napoleónicas inspiraron su plan para sofocar las juntas de gobierno locales (Guevara, 2013: 92).

Respecto de la actuación del virrey Fernando de Abascal, Guevara (2013) señala que se trató de un "gran virrey" y resalta que se negó a aceptar el ofrecimiento de convertirse en rey del Perú. Por el contrario, desde Lima, combatió las diferentes sublevaciones separatistas. Guevara opina que, gracias al esfuerzo de Abascal, España mantuvo sus colonias por dos lustros más (Guevara, 2013: 92).

A su turno, Lumbreras (2017) recuerda que, tras la reinstauración del absolutismo, el virrey Abascal anuló la Constitución de Cádiz, mientras que Norma (2016) destaca que su conocimiento del terreno y habilidad militar impidieron que los esfuerzos separatistas se coronasen con la emancipación. Por su parte, SM refiere la difícil situación del virrey quien, finalmente respetuoso de la ley, debió aplicar los considerandos de la Constitución de Cádiz, organizar campañas en contra de las juntas de gobierno de Quito y Chile, y ocuparse de zonas en disputa como el Alto Perú (SM, 2014: 100).

El tratamiento brindado por los manuales a la reacción absolutista nos ha parecido sobrio y adecuado. Respecto de la mirada nacionalista, 
es destacable que ninguno de los manuales construya, alrededor de las figuras de Fernando VII y Fernando de Abascal, la imagen de un otro hostil que amenaza al nosotros patriótico. Al contrario, el trato brindado a España y sus funcionarios es respetuoso. En tal sentido, se explica que el rey Fernando VII y el virrey Abascal procedieron conforme con los objetivos y principios que debían defender, al punto que al segundo se le considera un "gran virrey".

En lo referente a la posición del virreinato del Perú y de los peruanos en esta coyuntura, notamos que reaparece, levemente, la preocupación por explicar por qué se mantuvieron leales a España, mientras las demás colonias pugnaban por emanciparse. A esto se responde señalando que el virrey Abascal hizo de este virreinato el bastión del poder realista en América del Sur.

Respecto del repertorio político liberal, notamos que se prioriza la narración llana de los acontecimientos cuando estos, por la temática que tratan, constituyen una inmejorable ocasión de reforzar competencias ciudadanas, desarrollando explicaciones más amplias acerca de las características del sistema absolutista comparándolo con el liberalismo de entonces y el republicanismo por venir.

\section{Las actividades didácticas}

Seguidamente comentaremos las actividades didácticas de cuatro de los ocho textos que hemos utilizado para la presente investigación. Hemos seleccionado los textos de Guevara, Norma, Santillana, 2015 y SM por tratarse de manuales escolares. Los demás son manuales preuniversitarios o textos enciclopédicos de divulgación y sus secciones de actividades están muy poco desarrolladas.

\section{Guevara}

Guevara plantea dos preguntas que buscan inferir la razón de la instalación de las Cortes de Cádiz y de las Juntas de Gobierno en España y América, respectivamente. Estas podrían propiciar el debate del nuevo repertorio conceptual liberal, de acuerdo con la iniciativa del docente (2013: 70). Fuera de estas interrogantes, las actividades propuestas en el manual centran su atención en explicar por qué la postura del Perú en el proceso no fue abiertamente independentista, como en los demás virreinatos.

En tal sentido, hemos identificado una pregunta que lleva al equívoco, pues inquiere las razones por las que en el Perú no se instaló una Junta de Gobierno similar a la de Buenos Aires y Caracas. Como hemos visto, en 1814 se instaló la Junta del Cusco y las Provincias del Sur, por lo que el Perú sí contó con una institución análoga hasta el año 1815 (Guevara, 2013: 70). La mirada centralista, que tiende a generalizar la postura asumida por Lima, explicar este error de interpretación.

La otra preocupación que expresan las actividades didácticas del manual de Guevara se centra en la actuación de los diferentes estamentos durante el período de las Cortes de Cádiz. Así, se propone a los estudiantes relacionar El Mercurio Peruano $^{3}$ con una incipiente idea de nación criolla, al Inca Garcilaso con su homóloga mestiza, y se les induce a colegir que los objetivos de Túpac Amaru II y José de San Martín fueron distintos (Guevara, 2013: 60).

Aunque el texto de Guevara es sugerente, y le brinda al docente, y al estudiante, la oportunidad de discutir el nuevo repertorio liberal, la preocupación por lo nacional y lo social -explicar el desempeño de los peruanos y resaltar diferencias sociales- se impone en sus actividades didácticas.

\section{Norma}

Las actividades del texto de Norma preguntan al estudiante por qué el virreinato del Perú estuvo en contra de las Juntas de Gobierno. Refiere Norma la postura del virrey Abascal, quien convirtió al Perú en el bastión realista de Sudamérica (Norma, 2016: 85). Otras actividades inducen al estudio y reflexión del nuevo repertorio político liberal. En tal sentido, se inquiere la importancia de las Cortes, y la razón por la que el rey se opuso a las reformas liberales. Seguidamente, se propone la realización de un cuadro con los principales aportes de las Cortes y Juntas de Gobierno (Norma, 2016: 87).

La posición del Perú respecto de la Independencia también interesa a Norma que pregunta si su sociedad estuvo contra la Independencia, luego se plantea qué hubiese sucedido de triunfar los hermanos Angulo en el Cusco, coligiendo que la sociedad peruana 
emergente del proceso hubiese sido más integrada de lo que resultó tras la emancipación. Como se sabe, una idea fuerza acerca de la Independencia del Perú es que fue encabezada casi exclusivamente por criollos, por lo que su proyecto republicano excluyó a los indígenas. Concluye Norma, invitando al estudiante a preguntarse si estas sublevaciones perseguían la finalidad de separarse de España (Norma, 2016: 89).

\section{Santillana}

Santillana propone actividades didácticas relacionadas con el período de las Cortes de Cádiz. En su página 81 presenta un cuadro en el que el estudiante debe mencionar artículos de la Constitución de Cádiz, luego el principio político que cada uno representa, para finalmente expresar cuál era su finalidad. Después, sin embargo, repite el mismo error que Guevara e inquiere por qué en el Perú no se instalaron juntas de gobierno (Santillana, 2015: 82).

Santillana también se ocupa de la composición social de las rebeliones de Tacna, Huánuco y Cuzco, y pregunta cuál fue la participación criolla, mestiza e indígena en cada una de ellas. La actividad es bastante equilibrada si consideramos que en aquellas participaron diversos estamentos y castas, aunque posiblemente siguiendo programas políticos distintos (Santillana, 2015: 85).

\section{SM}

Cada unidad de SM contiene una sección llamada ciudadanos en acción donde se discuten temas relacionados con los valores y responsabilidad ciudadanos. Cuando se aborda la Independencia, el manual dedica tal sección a la actual Constitución Política del Perú. Sin embargo, las preguntas no apuntan a relacionar su capitulado con la Constitución de Cádiz de 1812, lo que hubiese resultado útil para establecer similitudes y diferencias, y descubrir desde cuándo se instalaron las ideas liberales en la sociedad (SM, 2014: 106).

Además, la sección de actividades de SM se ocupa de la participación de la mujer en la historia y, para el caso del período largo de la Independencia (de Túpac Amaru II hasta la Batalla de Ayacucho, 1780-1824), dedica una actividad al análisis del rol desempeñado por Micaela Bastidas, esposa de aquel, en dicha rebelión (SM, 2014: 59-60). El enfoque de género es pertinente y explícito en esta propuesta.

Sin embargo, la referida sección de actividades omite el período de las Cortes de Cádiz y salta de la Rebelión de Túpac Amaru II al período de la Independencia. A su turno, las llamadas del manual consultan a los estudiantes los cambios que la crisis española suscitó en Europa y América. Finalmente es destacable que SM, al comenzar su unidad respecto de la independencia, señale las competencias ciudadanas que busca incorporar en los estudiantes y que implican "(...) fortalecer los principios de equidad, justicia, igualdad, libertad" (SM, 2014: 90).

\section{Consideraciones finales}

Nuestra conclusión respecto de la manifestación de la ideología nacionalista en los textos escolares peruanos que tratan el período de las Cortes de Cádiz, es que dicha ideología, aunque presente, aparece muy atenuada. Así pues, no hemos encontrado ninguna animadversión hacia España. Al contrario, se propicia la comprensión de la situación peninsular desde la invasión napoleónica, y se desprende la idea de que el monarca Fernando VII defendía los intereses de su reino. Es el mismo caso del virrey Fernando de Abascal a quien, a pesar de reprimir los esfuerzos separatistas en la región, se le pondera como un funcionario que defendió los intereses de la Corona que servía.

En los manuales, la discusión de lo nacional se centra en lo siguiente: en el Perú, en sus efectos prácticos, la separación estamental de la sociedad colonial se mantuvo hasta bien entrado el siglo XX. Inclusive hoy, el debate sigue abierto. En tal sentido, la necesidad de establecer en qué consistió la participación de criollos, mestizos e indios, y la reiterada confrontación entre ellos, es reiterada en los textos escolares. En esa línea, sí hemos encontrado un leve sesgo anticriollo, y particularmente antilimeño, en algunos manuales. En tal sentido, la valoración de la actuación de los habitantes de Lima en el período, adolece de un análisis que permita la mejor comprensión de la particular situación de la capital virreinal en aquel contexto histórico. 
A contracorriente de lo señalado, el enfoque del período no deja de ser centralista y lleva a que algunos manuales le transfieran la postura de Lima a todo el Perú. Por ello, se afirma que en el virreinato del Perú no se estableció ninguna Junta de Gobierno, omitiendo la cusqueña. También es manifiesta la preocupación por explicar cierta renuencia peruana hacia el separatismo, cuando las rebeliones de Tacna, Huánuco y Cusco constituyen una respuesta adecuada a dicha inquietud.

Cuando los manuales tratan el período de las Cortes de Cádiz, parece pesar mucho la posterior confluencia de dos expediciones foráneas en el Perú para culminar con el proceso emancipador, las que los obliga a explicar, por adelantado, por qué fueron necesarias. De este modo, el debate tradicional de la Independencia del Perú, que se resume en la pregunta "¿nos independizaron o nos independizamos?" se asoma en los manuales, inclusive cuando se trata un período anterior a las corrientes emancipadoras.

Con relación al nuevo repertorio conceptual liberal, los manuales presentan variaciones de acuerdo con el período que tratan. La invasión napoleónica y las juntas se desarrollan con énfasis en el aprendizaje de los acontecimientos. Cuando se trata de las Cortes y la Constitución de Cádiz, la discusión del nuevo repertorio liberal se incrementa y, con él, la posibilidad de desarrollar competencias ciudadanas.

Luego, la presencia del repertorio liberal se debilita cuando se tratan las rebeliones anticoloniales, pues se asume que los movimientos separatistas lo incorporaron en sus programas y se centra la preocupación en discutir la postura de criollos, mestizos e indígenas en dichos eventos. De esta manera, se deja pasar la ocasión de confrontar los valores liberales con los absolutistas cuando se desarrolla la reacción conservadora del rey Fernando VII y el virrey Abascal.
En líneas generales, las actividades didácticas nos han parecido bastante adecuadas. Se puede observar, en ellas, esforzados diseños de enseñanza por competencias y la preocupación por desarrollar el juicio crítico de los estudiantes. Estas secciones podrían mejorarse si las unidades que atañen el período de las Cortes de Cádiz se propusiesen explícitamente desarrollar competencias ciudadanas relacionadas con los valores del liberalismo político y el republicanismo; también hemos notado la casi completa ausencia del enfoque de género, por lo que sugerimos a las editoras preguntarse más por el rol desempeñado por la mujer en este importante período histórico.

En líneas generales, podemos concluir que los manuales escolares de historia peruanos que tratan el período de las Cortes de Cádiz han sido elaborados con dedicación y profesionalismo. Evidenciar las grandes posibilidades que brinda esta temática para fortalecer la educación en competencias ciudadanas, mediante la discusión del nuevo repertorio conceptual liberal es un camino sencillo de recorrer. Tomar conciencia de que puede hacerse -asociando las competencias ciudadanas con la enseñanza de la historia- es el primer paso en este recorrido.

\section{Agradecimientos}

Nuestro agradecimiento al Instituto de Investigación Científica de la Universidad de Lima (IDIC) en la persona de su directora, la doctora Teresa Quiroz Velasco, por todo el apoyo brindado. También a la señorita Andrea Jiménez, estudiante de la carrera de comunicaciones en dicha casa de estudios, quien nos asistiera durante el transcurso de la pesquisa y organizó la información que en estas páginas compartimos con ustedes. 


\section{Referencias Citadas}

Abril, D.

2015 Ciudadanía, educación y complejidad: miradas desde la ecopedagogía. Revista Diálogo Andino No 47: 95-104, https://scielo.conicyt.cl/pdf/rda/n47/art10.pdf

Aguirre, J.

2015 El manual escolar como objeto de investigación en historia de la educación: apuntes al texto de geografía. Historia y Sociedad 28: 247-272.

Alarcón, L.

2013 Representaciones sobre la independencia en los manuales de Colombia. Investigación \& Desarrollo 21: 342-370.

Andújar Moreno, J.

2010 La constitución de Cádiz, las elecciones y los municipios. Revista Oficial del Poder Judicial 6: 303-309.

Arroyo, C. L.

2012 El rol de la Constitución de Cádiz en la gestación de la independencia del Perú. Historia Constitucional 13: 315-337.

Bonilla, $\mathrm{H}$.

2008 La experiencia del Perú con las juntas y la naturaleza de la participación política de la población nativa. Anuario de Historia Regional y de las Fronteras 13: $39-46$.

Campos, F. J. \& De Sevilla, F.

2012 La Constitución Española de 1812 y su recepción en Perú. e.Legal History Review 14: 1-28.

Carretero, M., \& González, M. F.

2004 Imágenes históricas y construcción de la identidad nacional: una comparación entre la Argentina, Chile y España. Aprender y Pensar la Historia 1: 173-195.

Catalani, F.

2003 El mal en la dialéctica de la alteridad. Revista Anclajes 7: 77-106.

Cayuela Fernández, J. G.

2011 Las Juntas Americanas ante la caída de la Junta Central en España (1809-1810). Actas del XVI Congreso Internacional de AHILA $\mathrm{N}^{\mathrm{o}} 33$, pp. 1-18. Universidad de Castilla La Mancha, San Fernando, España.

González, A. M.

2001 Republicanismo. Orígenes historiográficos y relevancia de un debate. Revista de Occidente 247: 121-145.

González, M.P.

2017 Los saberes históricos escolares como construcción situada y singular. Revista Diálogo Andino No 53, 2017: 45-57, https://scielo.conicyt.cl/pdf/rda/n53/0719-2681rda-53-00045.pdf

Guerra Martiniére, $\mathrm{M}$.

2018 Las Cortes de Cádiz y su impacto en el virreinato del Perú. Fondo Editorial del Congreso del Perú, Lima, Perú.

Hampe, $\mathrm{T}$.

2011 Sobre la Constitución de 1812: las Cortes gaditanas y su impacto en el Perú. En A. Ramos (Coord.), $L a$ Constitución de Cádiz y su huella en América (pp. 251258). Cádiz: Universidad de Cádiz.

Henríquez, R. \& Muñoz, Y.

2017 Leer y escribir históricamente: los desafíos pendientes de la enseñanza y del aprendizaje de la historia.
Revista Diálogo Andino No 53, 2017: 7- 21, https://scielo. conicyt.cl/pdf/rda/n53/0719-2681-rda-53-00007.pdf

Martínez, N.

2014 La historia de España en los recuerdos escolares. Murcia: Nau Libres.

Mc Evoy, C.

2018 [1997] La utopía republicana: ideales y realidades en la formación de la cultura política peruana (1871-1919) Fondo Editorial PUCP, Lima, Perú.

Ministerio de Educación [MINEDU]

2008 Diseño curricular nacional de educación básica regular, http://www.minedu.gob.pe/DeInteres/xtras/den_ 2009.pdf (3 julio 2018).

Ministerio de Educación [MINEDU]

2016 Currículo Nacional de Educación Básica, http://www. minedu.gob.pe/curriculo/pdf/curriculo-nacional-2016. pdf (5 de julio 2018).

Miralles, P. y Gómez, C.

2017 Enseñanza de la historia, Análisis de libros y construcción de identidades colectivas. Historia y Memoria de la Educación, 6: 9-28.

O'Phelan, S. R.

2016 1814: la junta de gobierno del Cuzco y el sur andino. Fondo Editorial PUCP, Lima, Perú.

Parodi, D.

2010 Lo que dicen de nosotros: la Guerra del Pacífico en la historiografía y textos escolares chilenos. Fondo Editorial PUCP, Lima, Perú.

Parodi, D.

2011 La Guerra del Perú y Chile contra España: olvidos y recuerdos de una gesta común. En Generación de diálogo Chile-Perú/Perú-Chile: documento 2: aspectos históricos, pp. 29-41. IDEI-PUCP, IEI Universidad de Chile, Konrad Adenauer Stiftung, Lima, Perú.

Parodi, D.

2017 Peruanos patriotas y chilenos fidelistas: Perú, Chile y la Independencia en la obra de Rubén Vargas Ugarte S.J. En La frontera disputada, editado por Aldo Panfichi, pp. 91-120. Fondo Editorial PUCP, Lima, Perú.

Parodi, D.

2019 Lo que decimos de ellos. La guerra del Pacífico en la historiografía y manuales escolares peruanos. Universidad de Lima. Lima, Perú.

Ruiz, V. P

2008 El impacto de las Cortes de Cádiz en el Perú. Un balance historiográfico. Revista de Indias. 68: 67-96.

Ruiz, V. P.

2000 La Independencia y la Cultura Política Peruana (1808-1821). IEP Ediciones, Lima.

Van Dijk, T. A.

1999 El análisis crítico del discurso. Revista Anthropos: Huellas del Conocimiento 186: 23-36.

Ramos, A.

2007 La Guerra de la Independencia y las Cortes de Cádiz en los manuales de Historia. En A. Ramos (Coord.), Lecturas sobre 1812, pp. 193-220. Cádiz: Universidad de Cádiz.

Ramos, A.

2007 Lecturas sobre 1812. Cádiz: Universidad de Cádiz. 
Ramos, A.

2015 El manifiesto de la Junta de Cádiz a la América española. En L. Funes (Coord.), Hispanismos del mundo (pp. 43-51). Buenos Aires: Miño y Dávila.

\section{Textos escolares}

\section{Guevara}

2013 Socio Mundo-Civilización: Historia, geografía y economía 3, Guía para el docente. eBiolibros, Lima.

Lumbreras

2017 Historia del Perú: una mirada actual del pasado. Lumbreras, Lima.

Norma

2016 Descubre ciencias sociales 3, Guía docente. Norma, Lima.
San Marcos

2017 Colección Compendio de Historia del Perú. San Marcos, Lima.

Santillana

2015 Historia, Geografía y Economía 3. Texto escolar. Santillana, Lima.

Santillana

2012 Guía Metodológica. Serie Hipervínculos: 3 Historia, SM

Geografía y Economía. Santillana, Lima.

2014 Proyecto encuentros: Historia, Geografía y Economía 3, Guía docente. SM, Lima.

Villanueva, J.

2010 Enciclopedia de historia del Perú. Bruño, Lima.

\section{Notas}

1 La presente pesquisa es parte de los esfuerzos que viene desarrollando el Grupo de Estudios Interdisciplinario acerca de Textos Escolares, Sociedad y Prácticas Educativas de la Universidad de Lima, el que es integrado por especialistas del Perú, Chile y Venezuela (http://www.ulima.edu. pe/instituto-de-investigacion-cientifica/grupo-de-estudios-interdisciplinario-sobre-textos-escolares).

2 Toda vez que los manuales escolares utilizados para la presente investigación se publicaron entre 2012 y 2016
(Lumbreras (2017) y San Marcos (2017) son manuales preuniversitarios y no escolares) hemos utilizado, para la presente investigación, el Diseño Curricular Nacional de Educación Básica Regular (2008), http://www. minedu.gob.pe/DeInteres/xtras/den_2009.pdf como marco general, y no el Currículo Nacional de Educación Básica de 2016, http://www.minedu.gob.pe/curriculo/ pdf/curriculo-nacional-2016.pdf, que comenzó a aplicarse en 2017. 
